Article

\title{
Antifungal Activity of an Abundant Thaumatin-Like Protein from Banana against Penicillium expansum, and Its Possible Mechanisms of Action
}

\author{
Wenxiao Jiao, Xiangxin Li, Handong Zhao, Jiankang Cao and Weibo Jiang * \\ College of Food Science and Nutritional Engineering, China Agricultural University, 17 Qinghuadonglu Road, \\ Beijing 100083, China; DC_COCOA@OUTLOOK.COM (W.J.); lixiangxin2016@163.com (X.L.); \\ h_d_zhao@sina.com (H.Z.); cjk@cau.edu.cn (J.C.) \\ * Correspondence: jwb@cau.edu.cn; Tel.: +86-010-6273-6565
}

Academic Editor: Steven L. Cobb

Received: 7 May 2018; Accepted: 29 May 2018; Published: 14 June 2018

\begin{abstract}
Thaumatin-like protein from banana (designated BanTLP) has been purified by employing a simple protocol consisting of diethylaminoethyl Sephadex (DEAE-Sephadex) chromatography, gel filtration on Sephadex G50, and reversed-phase chromatography. The purified protein was identified by MALDI-TOF mass spectrometry, with an estimated molecular weight of $22.1 \mathrm{kDa}$. BanTLP effectively inhibited in vitro spore germination of Penicillium expansum, one of the main postharvest pathogens in fruits. This study further investigated the antifungal properties and underlying mechanisms of BanTLP against P. expansum. Results demonstrated that BanTLP exhibited antifungal activity in a wide $\mathrm{pH}$ range $(4.0-10.0)$ at $20-50{ }^{\circ} \mathrm{C}$. Propidium iodide (PI) influx and potassium release confirmed that BanTLP induced membrane disruption of the test pathogen, increasing the membrane permeability and disintegration of the cell. This led to cell death, as evidenced by the assays of thiobarbituric acid-reactive species (TBARS) content, the production of reactive oxygen species (ROS), and 1,6-diphenyl-1,3,5-hexatriene (DPH) fluorescence integrity. Ultrastructural alterations in P. expansum conidia after BanTLP treatment revealed severe damage to the cell wall. These results suggest that BanTLP purified from banana exerts antifungal activity against $P$. expansum by inducing plasma membrane disturbance and cell wall disorganization.
\end{abstract}

Keywords: banana; thaumatin-like protein; antifungal activity; Penicillium expansum; mechanisms of action

\section{Introduction}

Banana (Musa acuminate) is considered to be one of the most important and popular fruits in the human diet due to its pleasant taste and its high nutritional value, in addition to its anti-hypertension, anti-diabetic, anti-ulcerogenic, anti-cancer, anti-proliferative, and antioxidant functions [1]. Research has shown that the pulp of ripe banana contains a great quantity of thaumatin-like protein (TLP) [2].

TLP, which belongs to pathogenesis-related (PR) protein family 5 (PR5 protein), shares an amino acid sequence with thaumatin (a sweet-tasting protein originally found in the arils of the ripe West African rain forest shrub Thaumatococcusdanielli), and is structurally similar [3]. TLPs are the products of a large, highly complex gene family containing fungal, plant, and animal TLPs. TLPs appear to possess biological functions such as antifungal, glucanase, and xylanase inhibition activities, and are considered to be involved in host defense, stress tolerance, and cell signaling [4-6]. Recently, many transgenic plants overexpressing TLPs have been developed for enhancing host resistance against pathogens, indicating that TLPs hold a great prospective for the molecular breeding of resistant plants [3].

TLPs isolated from banana, peach, and kiwifruit have been proven to be potent antifungal proteins [7-9]. However, this activity is reportedly lacking in other TLPs in plants [2,4]. An early 
study by Koiwa explained that the efficacy of TLPs depends on the combination of fungal species and TLP isoforms [10]. During the last two decades, much attention has been drawn to revealing the underlying mechanism of antifungal activity of TLPs, but to date it is still poorly understood. It has been reported previously that there is a direct relationship between the antifungal activities of TLPs and their ability to bind to several water-insoluble $\beta-1,3$-glucans, cell wall components of pathogenic fungi [4]. A molecular docking assay conducted by Liu further confirmed that Asp and Glu residues found in the cleft of soybean hulls TLP interacted with linear $\beta$-1,3-glucans through an inverting or retaining mechanism of glucan hydrolysis [11]. However, these previous studies focused on the analysis of the structure features underlying these antifungal activities, with emphasis on the molecular mechanism. Few studies have investigated the physiological and ultrastructural changes in fungi exposed to TLPs. This work will lead to new insights into the mechanism of action of the antifungal protein against fungi.

P. expansum is a devastating pathogen in fruit, leading to considerable economical losses during the postharvest storage and handling processes [12]. It has been reported that TLP purified from basrai banana can be used as a preservative in the food processing industry due to its inhibitory effect on the growth of Aspergillus phoenicis and Aspergillus flavus on white bread [7]. Another example for application of TLP would be the protection of rye bread against Penicillium requeforti, a major contaminating strain in the food processing industry [13]. To our knowledge, this work investigates for the first time the effect of BanTLP on the postharvest pathogen fungi (P. expansum) in order to promote the application of TLP for direct crop protection and gene engineering.

This study aimed to: (1) validate the antifungal activity of BanTLP isolated and purified from the banana fruit against $P$. expansum; and (2) observe the physiological and ultrastructural changes in P. expansum exposed to BanTLP and elucidate its mechanisms of action.

\section{Results and Discussion}

\subsection{Purification and Identification of Thaumatin-Like Protein from Banana (Ban TLP)}

BanTLP has been purified using a three-step chromatographic purification procedure consisting of anion-exchange chromatography, gel filtration, and reversed-phase chromatography, whereby the elutes were monitored by determining the absorbance at $280 \mathrm{~nm}$. A crude extract of banana fruit was applied to a DEAE-Sephadex A50 column eluted with a gradient of $\mathrm{NaCl}$ in the buffer, and three major fractions (A1, A2, and A3) were obtained (Figure 1A). A broad absorbance peak (A1) with immunocompetence against the BanTLP antibody was further purified by Sephadex G50 on the basis of molecular mass. After gel filtration, peak B1 was devoid of immunocompetence, and peaks B2 and B3 with immunocompetence were obtained (Figure 1B). The active fractions were pooled and subjected to reversed-phase chromatography on a $\mathrm{C} 5$ column, and peak $\mathrm{C} 2$ with immunocompetence was obtained (Figure 1C). The purity of BanTLP was confirmed by SDS-PAGE, which revealed that the purified protein consisted exclusively of a single polypeptide (Figure 1C, insert). The purified protein was identified as thaumatin-like protein with a molecular weight of $22.1 \mathrm{kDa}$ by mass spectrometry analysis (see Supplementary Materials Figure S1), and the Mascot score was 414 (greater than 77 is significant, $p<0.05$ ). A yield of $58 \mathrm{mg}$ of pure BanTLP was obtained from $1.5 \mathrm{~kg}$ of banana pulp (Table 1). This combination of different chromatograph techniques forms an efficient isolation method for bioactive compounds from plants, and is used extensively in protein purification. This work proposed a three-step chromatographic purification procedure to purify an abundant protein (BanTLP) from banana, which had similar chromatographic behaviors to thaumatin proteins purified from plants in previous studies $[2,9]$. 

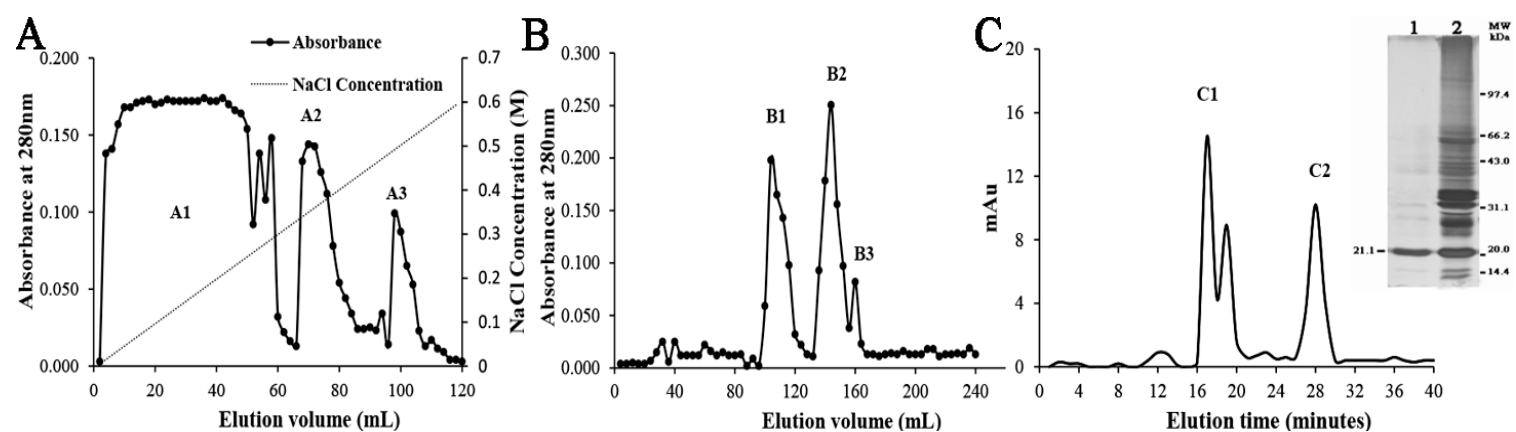

Figure 1. Purification of BanTLP. (A) Ion-exchange chromatography of the fraction of banana fruit extract (crude banana extract) with DEAE-Sephadex chromatography A50. The target protein was only observed in fraction A1. (B) Gel filtration of fraction A1 by fast protein liquid chromatography on a Sephadex G50 column. The target protein was observed in fractions B2 and B3. (C) The active fractions from gel filtration were pooled and used in a reverse-phase Supelco C5 column. The target protein was observed in fraction C2. (Insert) SDS-PAGE profiles of purified antifungal protein from banana fruit visualized using a silver-staining technique. Lane 1: the target protein; Lane 2: crude banana extract. Numbers on the right refer to molecular mass markers. MW represents the molecular weight marker.

Table 1. Protein yields at different stages of purification of thaumatin-like protein from banana (BanTLP).

\begin{tabular}{cc}
\hline Fraction & Total Protein from 1.5 kg Flesh (mg) \\
\hline Crude extract & 1038 \\
Unbound fraction from DEAE-Sephadex A50 & 648 \\
Major peak from Sephadex G50 chromatography & 261 \\
After reversed-phase chromatography & 58 \\
\hline
\end{tabular}

\subsection{Antifungal Properties of BanTLP against P. expansum}

TLPs are classified as forming part of the pathogenesis-related (PR) protein family 5 because they can be induced by biotic and abiotic stresses such as microbial infection, plant hormones, osmotic stress, and wounding. In previous study, TLPs were isolated and purified from various fruits. The antifungal protein isolated from kiwifruit showed a remarkable inhibitory effect on Botrytis cinerea and some suppressive effects on Mycosphaerella arachidicola and Coprinus comatus [9]. In another study, antifungal activity was observed in Verticillium albo-atrum, which exhibited sensitivity to BanTLP purified from banana [4]. However, so far, there are few detailed reports on the antifungal properties of TLP. Hence, this work examined its effects and the mechanisms involved. In the present study with BanTLP at $20 \mu \mathrm{M}$, the spore germination of P. expansum was reduced to about half that of the control, with a germination rate of $47 \%$. BanTLP at $60 \mu \mathrm{M}$ was able to completely inhibit the spore germination of P. expansum (Figure 2A) at $28^{\circ} \mathrm{C}$. Our result can be related to early reports described by Yasmin [7], who found that TLP isolated from banana inhibited the growth of Fusarium oxysporum, Aspergillus niger, Aspergillus fumigatus, and Trichoderma viride, with $\mathrm{IC}_{50}$ values of $9.7 \mu \mathrm{M}, 11.83 \mu \mathrm{M}, 4.61 \mu \mathrm{M}$, and $21.43 \mu \mathrm{M}$, respectively.

Sodium hypochlorite is an efficient and quick antifungal agent for commercial use. We investigated the effect of hypochlorite ( $0.05 \%$ of active chlorine) and BanTLP $(60 \mu \mathrm{M})$ on the germination of $P$. expansum conidia after $12 \mathrm{~h}$ of incubation at $28^{\circ} \mathrm{C}$, using hypochlorite as a positive control. The results showed that BanTLP was effective at reducing the spore germination by up to $100 \%$ after $8 \mathrm{~h}$ of exposure treatment of conidia, but the effect was less than that of hypochlorite, which repressed $100 \%$ the spore germination after just $2 \mathrm{~h}$ of treatment (Figure 2B). 

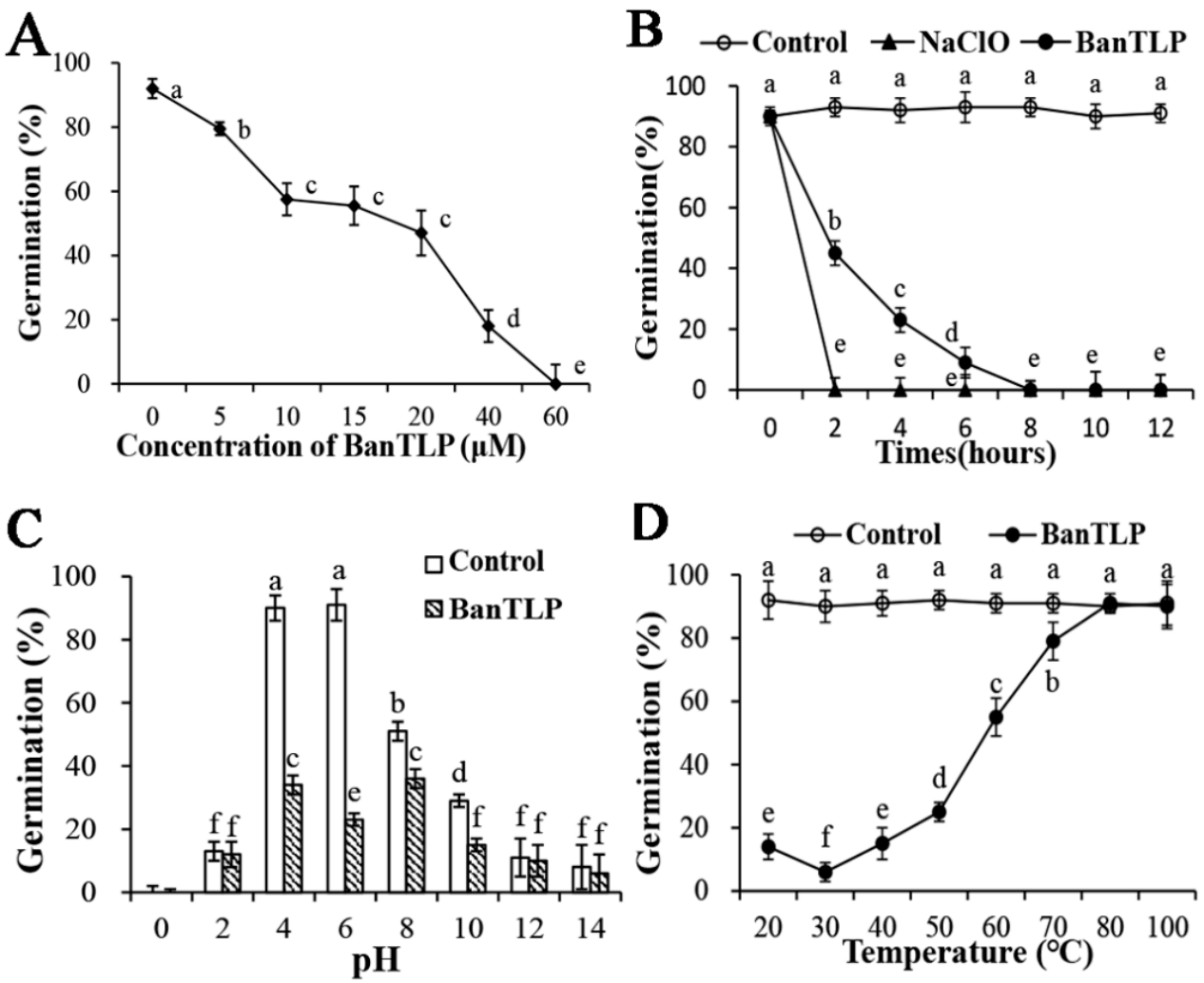

Figure 2. The effects of concentration (A), contact time (B), $\mathrm{pH}(\mathbf{C})$, and temperature (D) on the spore germination of Penicillium expansum exposed to BanTLP in potato dextrose broth (PDB). The germination rate of $P$. expansum was determined after $12 \mathrm{~h}$ of incubation at $28^{\circ} \mathrm{C}$. Each value is the mean of three replicates for two independent experiments. Vertical bars represent standard deviations of means. Those data marked with different letters are significantly different $(p<0.05)$ according to Duncan's multiple range test.

The biological functions of TLP can be directly influenced by $\mathrm{pH}$ and temperature, although its structure is considered to be stabilized due to the high number of disulfide bonds [14,15]. Results from this study indicated that the germination of P. expansum conidia was strongly inhibited both in control and treatment groups when $\mathrm{pH}$ values of the cultures media were lower than 2 or higher than 12, in agreement with the findings of Li (Figure 2C) [16]. After $12 \mathrm{~h}$ of exposure of the conidia, BanTLP significantly suppressed the germination of $P$. expansum conidia when $\mathrm{pH}$ values ranged from 4 to 10 , with an optimal antifungal activity at $\mathrm{pH} 6$. Additionally, a decrease in the antifungal activity was observed at $\mathrm{pH} 10$, and completely loss of antifungal activity occurred at higher $\mathrm{pH}$ values. The thermal stability of BanTLP was examined and the antifungal activity was stable at temperatures ranging from 20 to $50{ }^{\circ} \mathrm{C}$, with optimal antifungal activity at $30^{\circ} \mathrm{C}$ (Figure 2D). A comparison of the observations in this work with those of Ho indicates that antifungal activity of TLP isolated from emperor banana is more stable in a wider $\mathrm{pH}$ range ( $\mathrm{pH} 1$ to 11) and up to $70^{\circ} \mathrm{C}$ [17]. These differences may be ascribed to different fungal species and analysis methods. Similarly, Menu found that BanTLP isolated from banana exhibited endo- $\beta(1,3)$-glucanase activity in a $\mathrm{pH}$-dependent manner, with optimal activity at $\mathrm{pH} 5$ [4].

\subsection{Effect of BanTLP on Membrane Permeability and Disturbance in P. expansum}

The integrity of mycelia membrane of P. expansum was investigated after exposure to $60 \mu \mathrm{M}$ BanTLP by monitoring the propidium iodide (PI) influx. PI is a DNA-staining fluorescent probe that can enter the cell if the plasma membrane of cell is disrupted, resulting in a nucleus stained with a red fluorescent color [18]. Results in Figure 3A indicate that fluorescent intensity increased in conidia of 
P. expansum exposed to BanTLP as the incubation times extended. After $4 \mathrm{~h}$ of incubation with BanTLP, the percentage of PI fluorescent-stained conidia was $87 \%$, while that of the control was $14.2 \%$. After $6 \mathrm{~h}$ of incubation, $100 \%$ of conidia of P. expansum were stained in BanTLP-treated group, while only $18.3 \%$ were stained in the control group. The result of PI influx indicated that BanTLP is able to induce the plasma membrane disruption. The corresponding fluorescence images of PI influx is displayed in Supplementary Materials Figure S2.

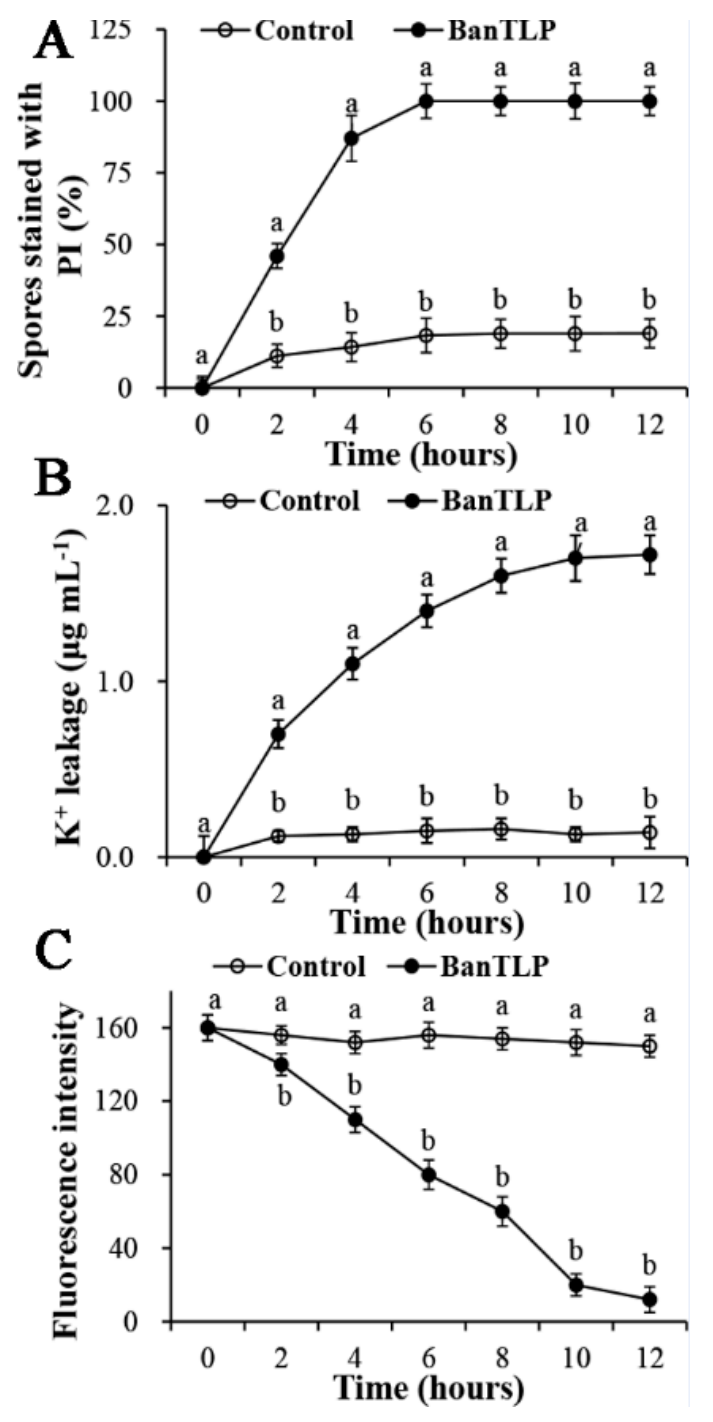

Figure 3. Effects of BanTLP at $60 \mu \mathrm{M}$ on the plasma membrane of P. expansum conidia as the exposure times extended. (A) Spores stained with propidium iodide (PI); (B) the leakage of intracellular potassium ions; (C) 1,6-diphenyl-1,3,5-hexatriene (DPH) fluorescence intensity of P. expansum. Each value is mean of three replicates for two independent experiments. Vertical bars represent standard deviations of means. Those data marked with different letters are significantly different $(p<0.05)$ between control and treatment groups at the same time according to Duncan's multiple range test.

The potassium ion release assay was conducted to estimate the permeability of the plasma membrane. Compelling evidence from early studies indicated that the plasma membrane of toxin-damaged cells became permeable for monovalent ions, with subsequent potassium ions release from the cell [19]. $\mathrm{K}^{+}$homeostasis may play a critical role in the maintenance of the membrane potential. Results in this study showed that the concentration of extracellular $\mathrm{K}^{+}$significantly increased in the initial $10 \mathrm{~h}$ of incubation with BanTLP. In contrast, for the control treatment, the concentration of 
extracellular $\mathrm{K}^{+}$was maintained at a low level throughout the experiment, with little $\mathrm{K}^{+}$release (Figure 3B).

A 1,6-diphenyl-1,3,5-hexatriene (DPH) fluorescence assay was performed to estimate the plasma membrane perturbation in terms of lipid bilayer. The DPH probe can be buried completely in the bilayer core with no effect on the membrane structure. Any disorder in the membrane lipid bilayer was a result of DPH parting from the membrane, with a subsequent decrease in the DPH fluorescent polarization [20]. The results in Figure 3C show that the DPH fluorescent intensity descended remarkably in conidia of P. expansum exposed to BanTLP as the incubation times extended. After $6 \mathrm{~h}$ of incubation, the fluorescent intensity of conidia exposed to BanTLP was $48.7 \%$ lower than that of the control $(p<0.05)$. The result indicated that BanTLP treatment perturbed the membrane lipid bilayer of the test fungus, resulting in DPH detachment and a decrease in fluorescent intensity. However, for the control treatment, the fluorescent intensity was maintained as the incubation times increased, indicating the membrane lipid bilayer was stable and well-organized.

Previous studies investigated a number of antifungal agents (such as isoquercitrin, monocaprin, citral, and so on) that directly or indirectly attack the plasma membranes of pathogenic fungi, providing much insight into membrane permeabilization [21,22]. Through PI influx, potassium ion leakage, and DPH assays, this study confirmed the hypothesis that BanTLP caused the damage of cell by inducing membrane permeabilization and disturbances. Some studies on the structure of TLPs isolated from plants supported the idea that the membrane-permeabilizing activity of TLP might be ascribed to its acidic cleft [10]. It has been demonstrated that when positively-charged TLP isolated from soy hulls and the negatively-charged microbial membranes are combined superficially and electrostatically, the TLP partially enters the hydrophobic part of cytoplasmic membranes [11]. Therefore, much research is needed to investigate the deeper mechanisms of BanTLP acting as a membrane-permeabilizing protein against $P$. expansum.

\subsection{Oxidative Stress in P. expansum Induced by BanTLP}

Reactive oxygen species (ROS) and thiobarbituric acid-reactive species (TBARS) are considered oxidative stress biomarkers. The accumulation of ROS molecules, including superoxide, hydrogen peroxide, and hydroxyl radicals, can lead to detrimental stress responses in fungi, disrupting the cell physiological status and causing oxidative death [23]. ROS were determined using a $2^{\prime}, 7^{\prime}$-dichlorofluorescein diacetate (DCFH-DA) fluorescent probe, which has proven efficiency for characterizing the overall ROS generation in many biological materials. As shown in Figure 4A,B, after $6 \mathrm{~h}$ of incubation with BanTLP, the percentage of cells marked with intracellular ROS in P. expansum increased 9.8-fold compared to the control. Moreover, when the incubation time was increased up to $12 \mathrm{~h}$, a 6.3-fold increase in the intracellular ROS generation was observed in the BanTLP treatment group compared to that of the control group $(p<0.05)$.

TBARS is the primary product of polyunsaturated fatty acids peroxidation, and can be used as an indicator of oxidative damage of the fungal plasma membrane. The variations in amounts of TBARS further confirmed the results from the ROS assay. When conidia of P. expansum were incubated with BanTLP at $28^{\circ} \mathrm{C}$ for $6 \mathrm{~h}$ or $12 \mathrm{~h}$, TBARS contents were 2.58- and 4.54-fold compared to that of the control, respectively $(p<0.05)$. Figure 4 C shows that TBARS contents in conidia of $P$. expansum prepared in BanTLP continuously increased as the contact times increased, whereas that of the control showed no variation throughout the experiment.

Similarly, the previous study demonstrated that osmotin, a tobacco PR-5 family protein, activated the RAS2/cAMP pathway and induced hyperproduction of intracellular ROS to promote programmed cell death of the yeast Saccharomyces cerevisiae [24]. Additionally, Hayea described a promising antifungal defensin, NaD1, with activity against Candida albicans because NaD1 induced ROS generation, leading to cell death as the result of oxidative damage [25]. Hence, BanTLP in this work promoted the accumulation of intracellular ROS, resulting in oxidative stress in P. expansum, which can be explained as another possible fungicidal action of BanTLP. 


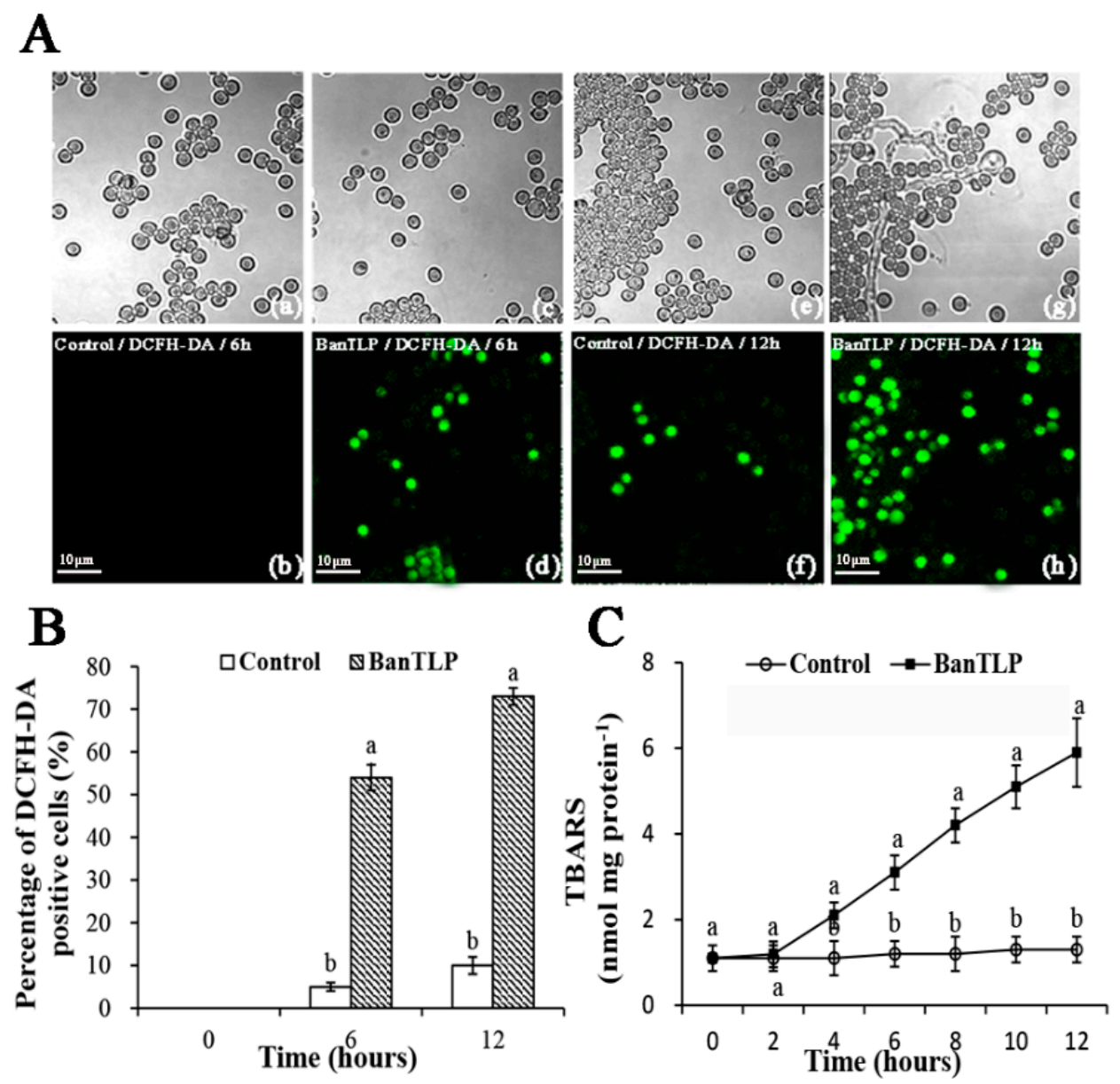

Figure 4. Effects of BanTLP at $60 \mu \mathrm{M}$ on oxidative stress of $P$. expansum. Figures panels show images of (A) the generation of intracellular reactive oxygen species (ROS), (B) the percentage of $2^{\prime}, 7^{\prime}$-dichlorofluorescein diacetate (DCFH-DA) positive cells, and (C) thiobarbituric acid-reactive species (TBARS) contents. The DCFH-DA fluorescent probe was visualized with the aid of fluorescence microscopy in P. expansum conidia treated with distilled water for $6 \mathrm{~h}(\mathbf{a}, \mathbf{b})$ and $12 \mathrm{~h}(\mathbf{e}, \mathbf{f})$ or treated with BanTLP for $6 \mathrm{~h}(\mathbf{c}, \mathbf{d})$ and $12 \mathrm{~h}(\mathbf{g}, \mathbf{h})$. Upper panels display the bright field images, while lower panels display the corresponding fluorescence images for the same field. The scale bar represents $10 \mu \mathrm{m}$. Each value is mean of three replicates for two independent experiments. Vertical bars represent standard deviations of means. Those data marked with different letters are significantly different $(p<0.05)$ between control and treatment groups at the same time according to Duncan's multiple range test.

\subsection{Effect of BanTLP on Cell Wall Integrity in P. expansum}

The effect of BanTLP on P. expansum cell wall was evaluated using a Calcofluor White (CFW) fluorescent probe. CFW can monitor abnormal chitin alterations located in the cell walls of fungi through a specific combination with chitin [26]. In this study, after being treated with BanTLP at $60 \mu \mathrm{M}$ for $6 \mathrm{~h}$, a bright blue fluorescent signal was detected. When the incubation time was increased to $12 \mathrm{~h}$, the bright blue fluorescence was enhanced in conidia cells in the treatment group. There was no apparent fluorescent signal in conidia cells in the control group throughout the experiment (Figure 5). The result from the present study indicated that BanTLP treatment severely damaged the cell wall of P. expansum conidia. Similarly, barley TLPs exerted their antifungal activity by binding to nascent $\beta-1,3$-glucans during fungal wall synthesis, preventing the growth of fungi [27]. The previous study confirmed that TLPs from plant could induce disruption of the fungal cell wall, leading to cell death. 

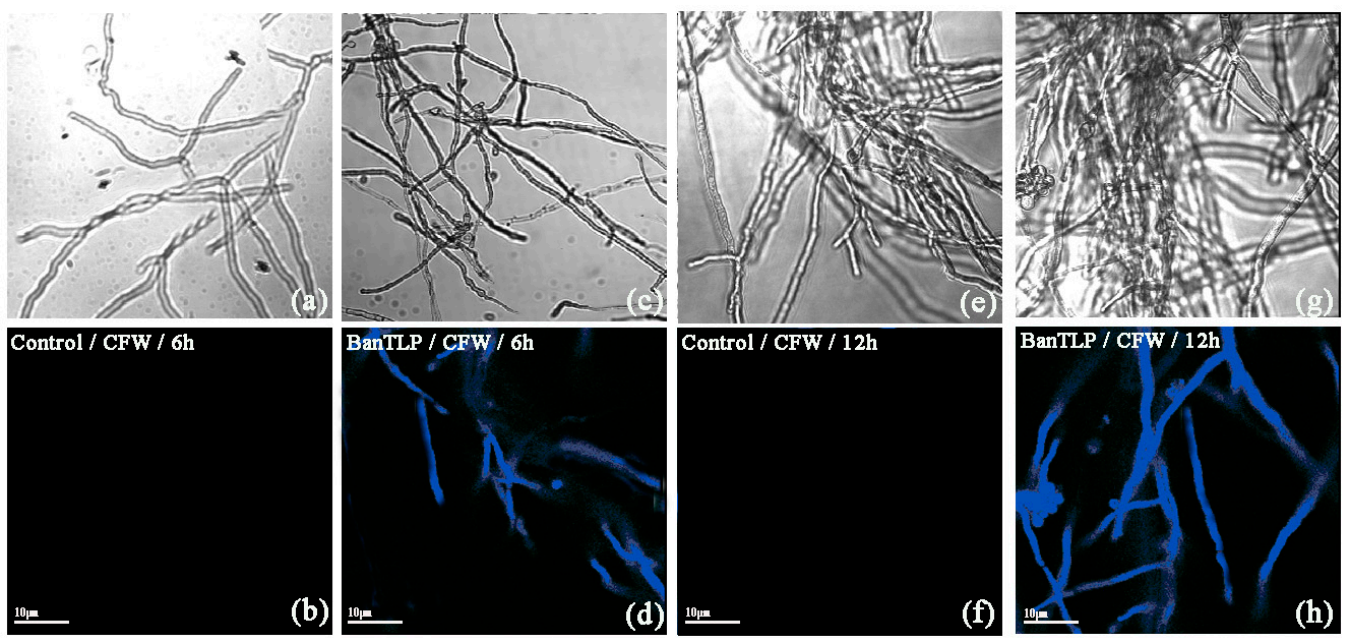

Figure 5. Effect of BanTLP at $60 \mu \mathrm{M}$ on the cell wall integrity of P. expansum conidia. The Calcofluor White (CFW) fluorescent probe was visualized with the aid of fluorescence microscopy in P. expansum conidia treated with distilled water for $6 \mathrm{~h}(\mathbf{a}, \mathbf{b})$ and $12 \mathrm{~h}(\mathbf{e}, \mathbf{f})$ or treated with BanTLP for $6 \mathrm{~h}(\mathbf{c}, \mathbf{d})$ and $12 \mathrm{~h}(\mathbf{g}, \mathbf{h})$. Upper panels display the bright field images, while lower panels display the corresponding fluorescence images for the same field. The scale bar represents $10 \mu \mathrm{m}$.

\subsection{Morphological and Ultrastructural Changes of P. expansum Conidia}

\subsubsection{Scanning Electron Microscope (SEM)}

In our work, other signs of damage to the cell wall of P. expansum conidia were found according to analysis with the aid of a scanning electron microscope. After $12 \mathrm{~h}$ of incubation at $28^{\circ} \mathrm{C}$, the conidia treated with distilled water displayed a normal and compact morphology (Figure 6a,b), whereas the conidia treated with BanTLP at $60 \mu \mathrm{M}$ showed irregular modifications. As shown in Figure $6 \mathrm{c}, \mathrm{d}$, cell surfaces of numerous conidia in the treatment group appeared to suffer from severe contraction and disruption.

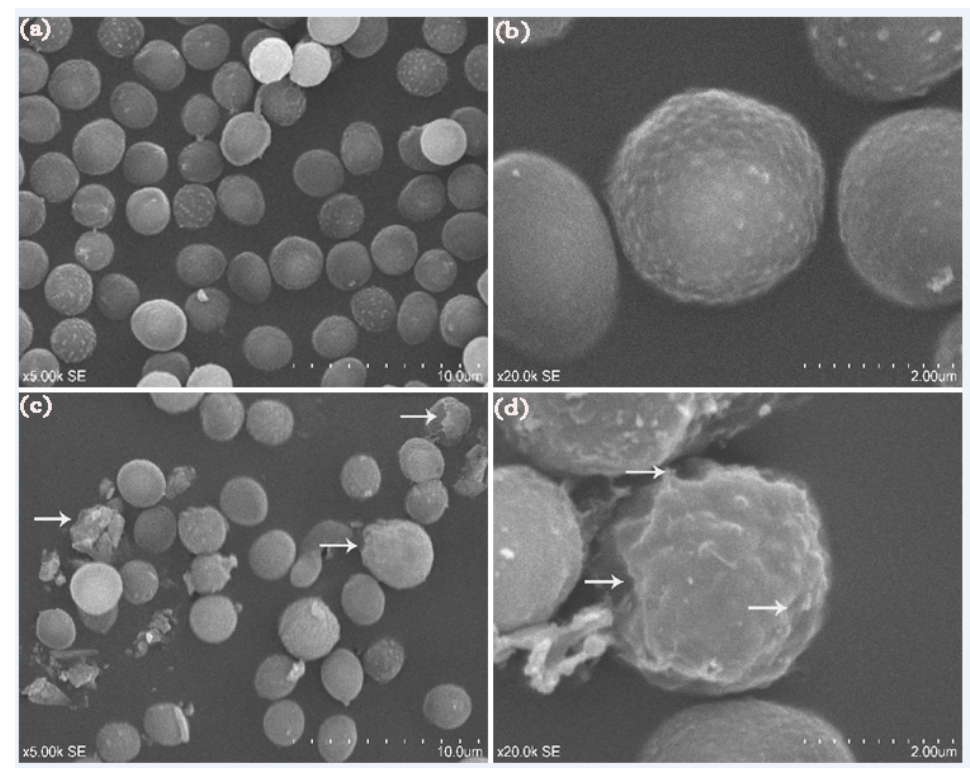

Figure 6. SEM of P. expansum. P. expansum conidia treated with distilled water $(\mathbf{a}, \mathbf{b})$, or BanTLP at $60 \mu \mathrm{M}(\mathbf{c}, \mathbf{d})$ for $12 \mathrm{~h}$. Arrows refer to the morphologic alterations in conidia, such as collapsed cell wall and severe contraction (magnification $\times 5000$, and 20,000). 


\subsubsection{Transmission Electron Microscope (TEM)}

The effect of BanTLP on the ultrastructural changes of P. expansum conidia was estimated using a transmission microscope. After $12 \mathrm{~h}$ of exposure treatment, the conidia treated with distilled water showed well-organized cells with a homogeneous cytoplasm, undamaged cell walls, integrated cell membranes, and normal organelles (Figure 7a). In contrast, for the treatment group, the vacuoles of the cells expanded and formed in large numbers, revealing an osmotic stress response in P. expansum conidia induced by BanTLP (Figure 7b,c). Additionally, the disorganization of cytoplasm and organelles was evident after BanTLP treatment (Figure 7d,e). A collapsed cell wall can be observed in Figure 7f,g. These ultrastructural changes in conidia may be attributed to enzymatic digestion of the cell wall and increasing membrane permeabilization, followed by the leakage of small molecular substances and ions, and cell metabolism disorder [22].
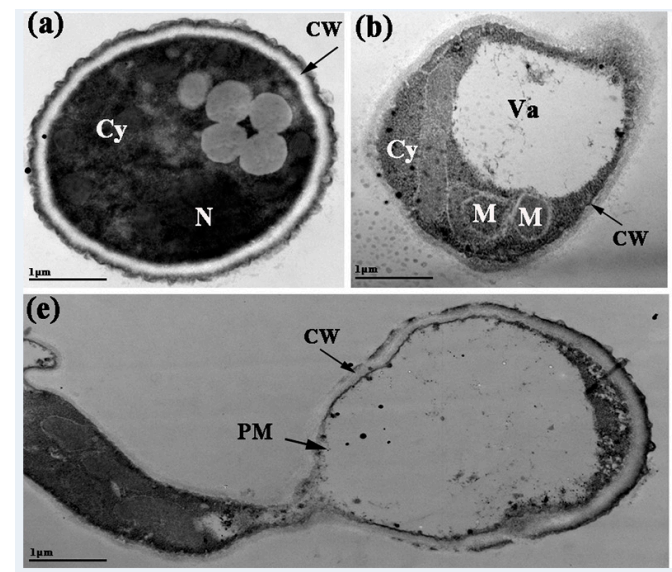
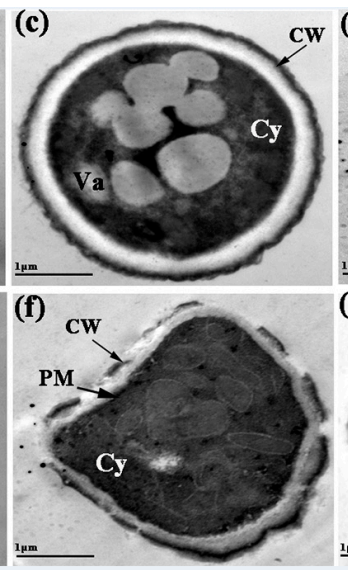

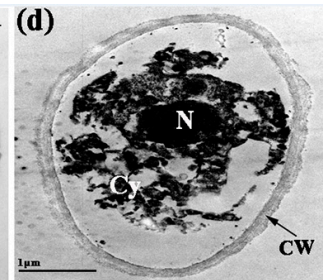

(g)

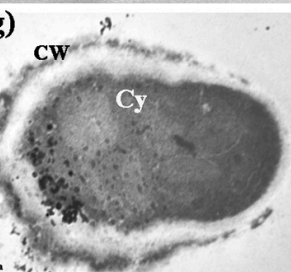

Figure 7. Ultrastructural changes of P. expansum observed by TEM. P. expansum conidia treated with distilled water $(\mathbf{a})$, or BanTLP at $60 \mu \mathrm{M}(\mathbf{b}-\mathbf{g})$ for $12 \mathrm{~h}$. The scale bar represents $1 \mu \mathrm{m}$. Each treatment was repeated three times, and at least two blocks were detected for each replicate. Va, vacuole; CW, cell wall; PM, plasma membrane; Cy, cytoplasm; N, nucleus; M, mitochondria. (Magnification $\times 30,000$ ).

\section{Materials and Methods}

\subsection{Fruit and Fungal Materials}

Banana (Musa acuminata) fruit were transported from Guangzhou to our laboratory at the China Agriculture University immediately after harvest, and stored at $20{ }^{\circ} \mathrm{C}$ for complete ripening.

The plant pathogen P. expansum was obtained from the microbiology lab of the China Agriculture University. The pathogen strain was cultivated in potato dextrose agar (PDA) at $28{ }^{\circ} \mathrm{C}$ for 7 days. Subsequently, the cultures were washed with sterile distilled water containing $0.05 \%(v / v)$ Tween-80. After filtration through four layers of sterile cheesecloth, the spore suspension was obtained in the absence of adherent mycelia. The concentration of spores was determined using a hemocytometer and calibrated to a final concentration at $1 \times 10^{6}$ spores $\mathrm{mL}^{-1}$.

\subsection{Purification and Identification of BanTLP from Banana}

Protein extraction was performed according to the method of $\mathrm{Xi}$ [28]. In brief, peeled banana $(1.5 \mathrm{~kg}$ ) was homogenized in $180 \mathrm{~mL}$ of $1 \mathrm{M}$ Tris ( $\mathrm{pH} \mathrm{11.2),} \mathrm{containing} 15 \%$ polyvinylpyrrolidone (PVPP). After centrifugation $\left(10,000 \times g, 30 \mathrm{~min}, 4^{\circ} \mathrm{C}\right)$, the supernatant was collected and dialyzed (MWCO 8000-14000, Serva dialysis tubing) against Tris- $\mathrm{HCl}$ buffer (5 mM Tris- $\mathrm{HCl}, \mathrm{pH} 7.5)$ at $4{ }^{\circ} \mathrm{C}$ for $12 \mathrm{~h}$. Subsequently, the crude extract was concentrated five-fold with the aid of a freeze-dryer. The protein content of the crude extract was estimated according to Bradford using bovine serum albumin (Sigma Aldrich, St. Louis, MO, USA) as standard [29]. 
The BanTLP was purified from the banana extract $(300 \mathrm{~mL})$ using a pre-equilibrated anion-exchange column (DEAE-Sephadex A50, $5 \times 5 \mathrm{~cm}$ ) in 30-mM Tris-HCl buffer with $\mathrm{pH}$ 8.0, and chromatography was performed in batches. The column was eluted with a gradient of $\mathrm{NaCl}$ from 0 to $0.6 \mathrm{M}$ in the same buffer at a flow rate of $1 \mathrm{~mL} \mathrm{~min}^{-1}$. After that, the immunocompetence of every fraction was measured through western blot assay with the rabbit antiserum against BanTLP in banana fruit [30]. Therefore, unbound proteins and the proteins eluted under the low concentration of $\mathrm{NaCl}$ from the ion-exchange chromatography (fraction A1) were pooled and collected. Subsequently, the fraction $\mathrm{A} 1$ was dialyzed against Tris- $\mathrm{HCl}$ buffer $(5 \mathrm{mM}$ Tris- $\mathrm{HCl}, \mathrm{pH} 7.5)$ at $4{ }^{\circ} \mathrm{C}$ for $12 \mathrm{~h}$, and then concentrated onto a gel filtration column $(70 \times 1.6 \mathrm{~cm})$ of Sephadex G50 equilibrated with 30-mM Tris-HCl buffer with $\mathrm{pH}$ 8.0, containing $0.1 \mathrm{M} \mathrm{NaCl}$. The column was eluted with the same buffer at a flow rate of $1 \mathrm{~mL} \mathrm{~min}{ }^{-1}$. The eluting peaks (fractions B2 and B3) with the primary antibody reacting bands were pooled and collected, and resolved on a C5 HPLC column $(250 \times 4.6 \mathrm{~mm}, 5 \mu \mathrm{m}$, Supelco, Bellefonte, PA, USA) equilibrated with $1 \%$ trifluoroacetic acid (TFA) in water. Proteins were eluted with a gradient of $0-70 \%$ acetonitrile in $0.1 \%$ TFA in $40 \mathrm{~min}$. The purified proteins were obtained by collecting protein fraction (C2) with immunocompetence, and dialyzed against Tris- $\mathrm{HCl}$ buffer $(5 \mathrm{mM}$ Tris- $\mathrm{HCl}, \mathrm{pH} 7.5)$ at $4{ }^{\circ} \mathrm{C}$ for $12 \mathrm{~h}$. The protein after dialysis was concentrated and stored in small aliquots at $-20^{\circ} \mathrm{C}$ until use.

Sodium dodecyl sulfate-polyacrylamide gel electrophoresis (SDS-PAGE) further confirmed that the purified protein contained only a single polypeptide according to the method described by Laemmli [31], using a miniprotean electrophoresis apparatus (Beijing Liuyi Instrument Factory DYY-151 7C, Beijing, China). The gel with protein bands was stained using a silver-staining technique according to Nesterenko [32].

Protein in-gel digestion assay was conducted according to Liu [11]. Identification of the protein depended on Matrix-assisted laser desorption ionization time-of-flight mass spectrometry (4700 MALDI-TOF/TOF Proteomics Analyzer, Applied Biosystems, Waltham, MA, USA). Mascot data base program (in-house MASCOT server v 2.1, Matrix Science Co., London, UK) was employed to analyze all spectra of proteins against the NCBInr database.

\subsection{Effect of BanTLP on Spore Germination of P. expansum}

Dose-dependent assay was performed by the exposure of spore germination of P. expansum to various concentrations of BanTLP following the method described previously [33]. Five concentrations of BanTLP at $0,5,10,15,20,40$, or $60 \mu \mathrm{M}$ were prepared in $5 \mathrm{~mL}$ of potato dextrose broth (PDB) in 10-mL glass tubes separately. After adding $100 \mu \mathrm{L}$ of $P$. expansum $\left(1 \times 10^{6}\right.$ spores $\left.\mathrm{mL}^{-1}\right)$ to each tube, samples were cultivated at $200 \mathrm{rpm}$ at $28{ }^{\circ} \mathrm{C}$ for $12 \mathrm{~h}$ and centrifuged $(8000 \times \mathrm{g})$ at $4{ }^{\circ} \mathrm{C}$ for 5 min. Afterwards, the conidia were rinsed twice with phosphate-buffered saline (PBS, pH 7.0) and resuspended with the same buffer. Approximately 200 spores per replicate were scored to calculate the germination rate of the test pathogen. The minimal inhibitory concentrations (MICs) of BanTLP against other three common postharvest fungi Rhizopus stolonifera, Botrytis cinerea, and Alternaria alternata were 60,60 , and $30 \mu \mathrm{M}$, respectively (Supplementary Materials Table S1). There were three replicates per treatment, and each experiment was repeated twice.

Minimum contact time between BanTLP and spores of P. expansum was evaluated following the description by Da with slight modifications [34]. The sterile distilled water (as negative control), $0.05 \%(v / v)$ sodium hypochlorite (as positive control), and BanTLP at $60 \mu \mathrm{M}$ were prepared in $5 \mathrm{~mL}$ of PDB containing P. expansum spore suspension $\left(1 \times 10^{6}\right.$ spores $\left.\mathrm{mL}^{-1}\right)$ in $10-\mathrm{mL}$ glass tubes. After $0,2,4,6,8,10$, or $12 \mathrm{~h}$ incubation in a shaker of $200 \mathrm{rpm}$ at $28^{\circ} \mathrm{C}$, the conidia were centrifuged $\left(8000 \times g, 5 \mathrm{~min}, 4^{\circ} \mathrm{C}\right)$, washed twice with $50 \mathrm{mM}$ PBS (pH 7.0) to remove the extra treatment solutions, and resuspended in $5 \mathrm{~mL}$ of PDB to a final concentration of $1 \times 10^{6}$ spores $\mathrm{mL}^{-1}$. The conidia were incubated in a shaker of $200 \mathrm{rpm}$ at $28^{\circ} \mathrm{C}$ for another $12,10,8,6,4,2$, or $0 \mathrm{~h}$ for the germination of spores, respectively. Finally, the germination rate was determined as described above. There were three replicates per treatment, and each experiment was repeated twice. 
The $\mathrm{pH}$ stability assay was conducted according to Da [34]. The BanTLP at $60 \mu \mathrm{M}$ were prepared in $5 \mathrm{~mL}$ of PDB in 10-mL glass tubes. Cultures were adjusted to different $\mathrm{pH}$ values ranging from 2.0 to 14.0 by the addition of $0.05 \mathrm{~N} \mathrm{HCl}$ or $2 \mathrm{~N} \mathrm{NaOH}$. PDB solutions without BanTLP at the same pH series were used as controls. Subsequently, $100 \mu \mathrm{L}$ of $P$. expansum $\left(1 \times 10^{6}\right.$ spores $\left.\mathrm{mL}^{-1}\right)$ were added to each tube and cultivated at $200 \mathrm{rpm}$ at $28^{\circ} \mathrm{C}$ for $12 \mathrm{~h}$. The germination rate of $P$. expansum was quantified with the method described above. There were three replicates per treatment, and each experiment was repeated twice.

Thermal stability assay was tested by heating BanTLP dissolved in $20 \mathrm{mM}$ Tris-HCl buffer (pH 7.0) at different temperatures, ranging from 20 to $100{ }^{\circ} \mathrm{C}$ for $30 \mathrm{~min}$ each in accordance with Theis with slight modifications [35]. With every $10^{\circ} \mathrm{C}$ of increasing temperature, the preincubated protein solutions were added to $5 \mathrm{~mL}$ of PDB, reaching a final concentration of $60 \mu \mathrm{M}$ in $10-\mathrm{mL}$ glass tubes. After adding $100 \mu \mathrm{L}$ of $P$. expansum $\left(1 \times 10^{6}\right.$ spores $\left.\mathrm{mL}^{-1}\right)$ to each tube, samples were cultivated at $200 \mathrm{rpm}$ at $28{ }^{\circ} \mathrm{C}$ for $12 \mathrm{~h}$. The germination rate of $P$. expansum was determined with the method described above. There were three replicates per treatment, and each experiment was repeated twice.

\subsection{Effect of BanTLP on the Plasma Membrane of P. expansum}

\subsubsection{PI Influx}

The membrane integrity of P. expansum spores was assayed according to Li and Tian with slight modifications [36]. Thus, $100 \mu \mathrm{L}$ of spore suspensions were transferred to $5 \mathrm{~mL}$ of sterile distilled water (as control) or $60 \mu \mathrm{M}$ BanTLP to obtain a final concentration of $1 \times 10^{6}$ spores $\mathrm{mL}^{-1}$. After incubation in a shaker of $200 \mathrm{rpm}$ at $28^{\circ} \mathrm{C}$ for $0,2,4,6,8,10$, or $12 \mathrm{~h}$, the conidia were centrifuged $(8000 \times g$, $5 \mathrm{~min}, 4^{\circ} \mathrm{C}$ ), and washed twice with $50 \mathrm{mM}$ PBS (pH 7.0) to remove the extra mycelia. Subsequently, the spore suspensions were treated with $10 \mu \mathrm{g} \mathrm{mL}^{-1}$ PI (Sigma Aldrich, USA) and incubated in the dark at $30{ }^{\circ} \mathrm{C}$ for $5 \mathrm{~min}$. After centrifugation $\left(8000 \times g, 5 \mathrm{~min}, 4{ }^{\circ} \mathrm{C}\right)$, spores were washed twice with $50 \mathrm{mM}$ PBS ( $\mathrm{pH}$ 7.0) to remove residual dye, collected, and resuspended in the same buffer for the observation, with the aid of a confocal laser scanning microscopy (Olympus, Fluoview FV1000 Espectral, Tokoy, Japan) equipped with an Olympus digital camera at 546-nm excitation and 590-nm emission wavelengths. The percentage of spores stained with PI was calculated as a proportion of the total spore number, and the number of spores in the bright-field was defined as the total spore number. There were three replicates per treatment, and three fields of view from each microscope slide were randomly chosen and observed.

\subsubsection{Potassium Release Assay}

Potassium release assay was used to assess the concentration of free potassium ions in suspensions of $P$. expansum spores with the method described previously [37]. The spores exposed to sterile distilled water (as control) or $60 \mu \mathrm{M}$ BanTLP were incubated in a shaker of $200 \mathrm{rpm}$ at $28^{\circ} \mathrm{C}$ for the time intervals described above. After centrifuging at $8000 \times g$, for $5 \mathrm{~min}$, the supernatant was collected and used to determine the concentration of extracellular potassium ions with the aid of graphite furnace flame atomic absorption spectroscopy (GFAAS8000, Skyray Instrument, Suzhou, China). The unit of concentration of extracellular free potassium ions was expressed as $\mu \mathrm{g} \mathrm{mL}^{-1}$.

\subsubsection{Fluorescence Intensities Assay Related to the Membrane Disturbance}

Alterations of membrane dynamics were evaluated through fluorescence assay with a DPH probe (Aladdin Industrial Corporation, Los Angeles, CA, USA) according to Yun with slight modifications [38]. Briefly, P. expansum spores $\left(1 \times 10^{6} \mathrm{~mL}^{-1}\right)$ were exposed to sterile distilled water (as control) or $60 \mu \mathrm{M}$ BanTLP and incubated in a shaker of $200 \mathrm{rpm}$ at $28^{\circ} \mathrm{C}$ for $0,2,4,6,8,10$, or $12 \mathrm{~h}$. Subsequently, the conidia were centrifuged $\left(8000 \times \mathrm{g}, 5 \mathrm{~min}, 4^{\circ} \mathrm{C}\right)$, washed twice with $50 \mathrm{mM}$ PBS ( $\mathrm{pH} 7.0$ ), and then fixed with $0.37 \%$ formaldehyde. After freezing with liquid nitrogen and thawing with PBS twice, the samples were incubated with $0.5 \mathrm{mM} \mathrm{DPH}$ for $50 \mathrm{~min}$ at $30{ }^{\circ} \mathrm{C}$ and washed with 
the same buffer thrice. The conidia were resuspended with PBS and used for the determination of DPH fluorescence intensity with a spectrofluorophotometer (SHIMADZU, RF-5301PC, Kyoto, Japan) at excitation and emission wavelengths of $350 \mathrm{~nm}$ and $425 \mathrm{~nm}$, respectively.

\subsubsection{ROS Determination}

Spores were treated in the same way as Section 3.4.1 described above and incubated in a shaker of $200 \mathrm{rpm}$ at $28^{\circ} \mathrm{C}$ for 6 or $12 \mathrm{~h}$. The samples were centrifuged $\left(8000 \times g, 5 \mathrm{~min}, 4^{\circ} \mathrm{C}\right)$, and washed twice with $50 \mathrm{mM}$ PBS (pH 7.0). Subsequently, the spores of P. expansum stained with $10 \mu \mathrm{M}$ DCFH-DA (Sigma Aldrich, USA) at $37^{\circ} \mathrm{C}$ in the dark for 20 min were used to evaluate the generation of ROS in the cell according to Cerioni [39]. After washing twice with PBS, spores were resuspended with the same buffer to a final concentration of $1 \times 10^{6}$ spores $\mathrm{mL}^{-1}$. The samples were viewed by fluorescence at $525 \mathrm{~nm}$ when excited at $488 \mathrm{~nm}$ with confocal laser scanning microscopy. The percentage of positive cells stained by DCFH-DA dye was calculated as a proportion of the total spore number, and the number of spores in bright-field was defined as the total spore number. There were three replicates per treatment, and three fields of view from each microscope slide were observed.

\subsubsection{Determination of TBARS}

Spores were treated in the same way as Section 3.4.1 described above and incubated in a shaker of $200 \mathrm{rpm}$ at $28^{\circ} \mathrm{C}$ for $0,2,4,6,8,10$, or $12 \mathrm{~h}$, centrifuged $\left(8000 \times g, 5 \mathrm{~min}, 4^{\circ} \mathrm{C}\right)$, and then washed twice with $50 \mathrm{mM}$ PBS (pH 7.0). Subsequently, the conidia were subjected to an ultrasound bath thrice for ten minutes each to break the conidia. TBARS were evaluated according to Cerioni [39]. Firstly, $1 \mathrm{~mL}$ of conidial extract was mixed with $1 \mathrm{~mL}$ of pre-cold $20 \%$ trichloroacetic acid (TCA) $(w / v)$. After centrifugation $\left(19,800 \times g, 5 \mathrm{~min}, 4^{\circ} \mathrm{C}\right), 2 \mathrm{~mL}$ of a saturated solution containing thiobarbituric acid (TBA) in $0.1 \mathrm{M} \mathrm{HCl}$ and $10 \mathrm{mM}$ of butylated hydroxytoluene were added to the supernatant, which was then incubated in a water bath at $100{ }^{\circ} \mathrm{C}$ for $60 \mathrm{~min}$. After cooling at room temperature, the reaction mixture was used to determine the absorbance at $535 \mathrm{~nm}$ against a control cuvette in the absence of conidial extract. A molar extinction coefficient of $156 \mathrm{mmol} \mathrm{cm}^{-1}$ was employed to calculated the concentration of TBARS. There were three replicates per treatment, and the experiment was performed twice. The resulted was expressed as nmol $\mathrm{mg}$ protein.

\subsection{Effect of BanTLP on Cell Wall Integrity of P. expansum}

The integrity of P. expansum spores cell walls was evaluated in accordance with Wang, with some modifications [40]. Thus, $100 \mu \mathrm{L}$ of spore suspensions were transferred into $20 \mathrm{~mL}$ of PDB in sterile conical flasks $(50 \mathrm{~mL})$ to reach a final concentration of $1 \times 10^{5}$ spores $\mathrm{mL}^{-1}$, and cultivated at $200 \mathrm{rpm}$ at $28{ }^{\circ} \mathrm{C}$ for $72 \mathrm{~h}$. Subsequently, mycelia were obtained in paper filter $(0.2 \mu \mathrm{m})$ and resuspended with $5 \mathrm{~mL} 50 \mathrm{mM}$ PBS (pH 7.0) in a 10-mL sterile glass tube. BanTLP was then added to reach final concentrations of $60 \mu \mathrm{M}$. PBS without the antifungal protein served as the control. After incubation at $200 \mathrm{rpm}$ at $28^{\circ} \mathrm{C}$ for $6 \mathrm{~h}$ or $12 \mathrm{~h}$, samples were collected by centrifugation at $8000 \times g$ for $10 \mathrm{~min}$ at $4{ }^{\circ} \mathrm{C}$, and washed twice with $50 \mathrm{mM}$ PBS (pH 7.0). Subsequently, the mycelia were stained with $50 \mu \mathrm{g}$ $\mathrm{mL}^{-1} \mathrm{CFW}$ fluorescent dye (Aladdin Industrial Corporation, USA) in the dark for $15 \mathrm{~min}$. The mycelia were visualized with the aid of confocal laser scanning microscopy at 395-nm excitation and 440-nm emission wavelengths. There were three replicates per treatment, and three fields of view from each microscope slide were observed.

\subsection{Morphological and Ultrastructural Changes of P. expansum Conidia}

\subsubsection{SEM}

The sterile distilled water (as control) or BanTLP at $60 \mu \mathrm{M}$ was prepared in $50 \mathrm{mM}$ PBS (pH 7.0). Subsequently, $100 \mu \mathrm{L}$ of $P$. expansum spores $\left(1 \times 10^{6}\right.$ spores $\left.\mathrm{mL}^{-1}\right)$ were added to each tube and incubated at $200 \mathrm{rpm}$ at $28^{\circ} \mathrm{C}$ for $12 \mathrm{~h}$. Then, spores were collected after centrifugation $(8000 \times g, 5 \mathrm{~min}$, 
$4{ }^{\circ} \mathrm{C}$ ), and washed with $50 \mathrm{mM}$ PBS (pH 7.0) thrice. Then, samples were fixed with $3 \%$ glutaraldehyde in $50 \mathrm{mM}$ PBS ( $\mathrm{pH} 7.0$ ) at room temperature for $4 \mathrm{~h}$ without agitation and rinsed with PBS four times for $20 \mathrm{~min}$ each. After post-fixing in 1\% osmic acid at room temperature for $2 \mathrm{~h}$, the samples were washed with double distilled water twice for $15 \mathrm{~min}$. Samples were dehydrated through a graded alcohol series of $30 \%, 50 \%, 70 \%, 80 \%, 90 \%$, and $95 \%$, then thrice at $100 \%$ for $15 \mathrm{~min}$ in each series. Following this, samples were incubated in isoamyl acetate overnight. Samples were then subjected to a critical point of dry carbon dioxide and coated with gold. Observation using a scanning electron microscope (S-3400N, SEM system, Hitachi, Tokyo, Japan) was carried out at the College of Biological Science at China Agriculture University.

\subsubsection{TEM}

Samples were prepared as described for SEM. After fixation with $2 \%$ glutaraldehyde at room temperature for $4 \mathrm{~h}$ without agitation, the samples were post-fixed in $1 \%$ osmic acid at room temperature for $2 \mathrm{~h}$ with a gentle shake once and rinsed with PBS twice for $15 \mathrm{~min}$. Afterwards, samples were subjected to dehydration with a graded alcohol series of 30\%, 50\%, 70\%, 80\%, 90\%, $95 \%$, and $100 \%(v / v)$ for $15 \mathrm{~min}$, respectively, and washed with $100 \%(v / v)$ acetone thrice for $10 \mathrm{~min}$ each. After resin infiltration at $35{ }^{\circ} \mathrm{C}$ overnight, the ultrathin sections $(50-90 \mathrm{~nm})$ were made by using an ultramicrotome with a diamond knife, stained with uranyl acetate solution and lead citrate, and visualized in a transmission electron microscope (H-7500, TEM system, Hitachi, Japan) according to Li [41].

\subsection{Statistical Analysis}

All experiments were performed according to a completely randomized design with three replicates per treatment. The data were subjected to analysis of variance and Duncan's new multiple range tests to test any significant differences between the means at $5 \%$ significance level. Data were evaluated with SPSS Statistics software 19.0 (Chicago, IL, USA).

\section{Conclusions}

In this work, 22.1 -kDa TLPs isolated from banana significantly inhibited postharvest fungus P. expansum in a wide $\mathrm{pH}$ range (4.0-10.0), and at $20-50{ }^{\circ} \mathrm{C}$. Based on determination of physiological parameters and observations of morphological changes in P. expansum exposed to BanTLP, the antifungal protein attacked the cell membranes and induced membrane permeabilization and disturbance. In addition, BanTLP targeted and disrupted cell wall of the test fungus, leading to cell death. Hence, BanTLP acts as a potent antifungal agent with the potential for direct crop protection and the development of pathogen-resistant transgenic plants. However, further research is necessary to elucidate more biological functions of BanTLP in situ in order to highlight its complex mechanisms of host defense resistance against pathogens.

Supplementary Materials: The following are available online. The Mascot search results of BanTLP purified from banana, Table S1: The minimal inhibitory concentrations (MIC) $(\mu \mathrm{M})$ of BanTLP against four common postharvest fungi, Figure S2: The effect of BanTLP at $60 \mu \mathrm{M}$ on the membrane of P. expansum conidia by analyzing PI influx.

Author Contributions: Data curation, W.Jiao; Investigation, W.Jiao and H.Z.; Project administration, W.Jiao and X.L.; Supervision, W.Jiang; Writing—original draft, W.Jiao; Writing—review and editing, J.C.

Acknowledgments: This work was supported by the National Basic Research Program of China ('973’ program, No. 2013CB127106).

Conflicts of Interest: The authors declare no conflict of interest. 


\section{References}

1. Tsamo, C.V.P.; Herent, M.F.; Tomekpe, K.; Emaga, T.H.; Quetin-Leclercq, J.; Rogez, H.; Larondelle, Y.; Andre, C. Phenolic profiling in the pulp and peel of nine plantain cultivars (Musa sp.). Food Chem. 2015, 167, 197-204. [CrossRef] [PubMed]

2. Barre, A.; Peumans, W.J.; Menu-Bouaouiche, L.; Damme, E.J.; May, G.D.; Herrera, A.F.; Leuven, F.V.; Rougé, P. Purification and structural analysis of an abundant thaumatin-like protein from ripe banana fruit. Planta 2000, 211, 791-799. [CrossRef] [PubMed]

3. Liu, J.J.; Sturrock, R.; Ekramoddoullah, A.K.M. The superfamily of thaumatin-like proteins: Its origin, evolution, and expression towards biological function. Plant Cell Rep. 2010, 29, 419-436. [CrossRef] [PubMed]

4. Menu, L. A molecular basis for the endo- $\beta 1$, 3-glucanase activity of the thaumatin-like proteins from edible fruits. Biochimie 2003, 85, 123-131. [CrossRef]

5. Grenier, J.; Potvin, C.; Asselin, A. Some Fungi Express $\beta-1,3-$ Glucanases Similar to Thaumatin-like Proteins. Mycologia 2000, 92, 841-848. [CrossRef]

6. Tian, B.; Harrison, R.; Morton, J.; Jaspers, M.; Hodge, S.; Grose, C.; Trought, M. Extraction of Pathogenesis-Related Proteins and Phenolics in Sauvignon Blanc as Affected by Grape Harvesting and Processing Conditions. Molecules 2017, 22, 1164. [CrossRef] [PubMed]

7. Yasmin, N.; Saleem, M. Biochemical characterization of fruit-specific pathogenesis-related antifungal protein from basrai banana. Microbiol. Res. 2014, 169, 369-377. [CrossRef] [PubMed]

8. Palacín, A.; Tordesillas, L.; Gamboa, P.; Sanchez-Monge, R.; Cuesta-Herranz, J.; Sanz, M.L.; Barber, D.; Salcedo, G.; Díaz-Perales, A. Characterization of peach thaumatin-like proteins and their identification as major peach allergens. Clin. Exp. Allergy 2010, 40, 1422-1430. [CrossRef] [PubMed]

9. Wang, H.; $\mathrm{Ng}$, T.B. Isolation of an antifungal thaumatin-like protein from kiwi fruits. Phytochemistry 2002, 61, 1-6. [CrossRef]

10. Koiwa, H.; Kato, H.; Nakatsu, T.; Oda, J.; Yamada, Y.; Sato, F. Crystal structure of tobacco PR-5d protein at 1.8 A resolution reveals a conserved acidic cleft structure in antifungal thaumatin-like proteins. J. Mol. Biol. 1999, 286, 1137-1145. [CrossRef] [PubMed]

11. Liu, C.; Cheng, F.; Sun, Y.; Ma, H.; Yang, X. Structure-Function Relationship of a Novel PR-5 Protein with Antimicrobial Activity from Soy Hulls. J. Agric. Food Chem. 2016, 64, 948-959. [CrossRef] [PubMed]

12. Vilanova, L.; Viã As, I.; Torres, R.; Usall, J.; Jauset, A.M.; Teixidã, N. Infection capacities in the orange-pathogen relationship: Compatible (Penicillium digitatum) and incompatible (Penicillium expansum) interactions. Food Microbiol. 2012, 29, 56-66. [CrossRef] [PubMed]

13. Sørensen, H.P.; Madsen, L.S.; Petersen, J.; Andersen, J.T.; Hansen, A.M.; Beck, H.C. Oat (Avena sativa) seed extract as an antifungal food preservative through the catalytic activity of a highly abundant class I chitinase. Appl. Biochem. Biotechnol. 2010, 160, 1573-1584. [CrossRef] [PubMed]

14. Ghosh, R.; Chakrabarti, C. Crystal structure analysis of NP24-I: A thaumatin-like protein. Planta 2008, 228, 883. [CrossRef] [PubMed]

15. Fierens, E.; Gebruers, K.; Voet, A.R.; De Maeyer, M.; Courtin, C.M.; Delcour, J.A. Biochemical and structural characterization of TLXI, the Triticum aestivum L. thaumatin-like xylanase inhibitor. J. Enzyme Inhib. Med. Chem. 2009, 24, 646-654. [CrossRef] [PubMed]

16. Li, B.; Lai, T.; Qin, G.; Tian, S. Ambient pH Stress Inhibits Spore Germination of Penicillium expansum by Impairing Protein Synthesis and Folding: A Proteomic-Based Study. J. Proteome Res. 2010, 9, $298-307$. [CrossRef] [PubMed]

17. Ho, V.; Wong, J.T. A thaumatin-like antifungal protein from the emperor banana. Peptides 2007, 28, 760-766. [CrossRef] [PubMed]

18. Wang, L.; Wu, H.; Qin, G.; Meng, X. Chitosan disrupts Penicillium expansum and controls postharvest blue mold of jujube fruit. Food Control 2014, 41, 56-62. [CrossRef]

19. Yu, S.P. Regulation and critical role of potassium homeostasis in apoptosis. Prog. Neurobiol. 2003, 70, 363-386. [CrossRef]

20. Repáková, J.; Holopainen, J.M.; Morrow, M.R.; Mcdonald, M.C.; Čapková, P.; Vattulainen, I. Influence of DPH on the Structure and Dynamics of a DPPC Bilayer. Biophys. J. 2005, 88, 3398-3410. [CrossRef] [PubMed] 
21. Ma, M.; Wen, X.; Xie, Y.; Guo, Z.; Zhao, R.; Yu, P.; Gong, D.; Deng, S.; Zeng, Z. Antifungal activity and mechanism of monocaprin against food spoilage fungi. Food Control 2017, 84, 561-568. [CrossRef]

22. Zheng, S.; Jing, G.; Xiao, W.; Ouyang, Q.; Lei, J.; Tao, N. Citral exerts its antifungal activity against Penicillium digitatum by affecting the mitochondrial morphology and function. Food Chem. 2015, 178, 76-81. [CrossRef] [PubMed]

23. Duprécrochet, S.; Erard, M.; Nüße, O. ROS production in phagocytes: Why, when, and where? J. Leukoc. Biol. 2013, 94, 657-670. [CrossRef] [PubMed]

24. Narasimhan, M.L.; Coca, M.A.; Jin, J.; Yamauchi, T.; Ito, Y.; Kadowaki, T.; Kim, K.K.; Pardo, J.M.; Damsz, B.; Hasegawa, P.M. Osmotin is a homolog of mammalian adiponectin and controls apoptosis in yeast through a homolog of mammalian adiponectin receptor. Mol. Cell 2005, 17, 171-180. [CrossRef] [PubMed]

25. Hayes, B.M.E.; Bleackley, M.R.; Wiltshire, J.L.; Anderson, M.A.; Traven, A.; van der Weerden, N.L. Identification and Mechanism of Action of the Plant Defensin NaD1 as a New Member of the Antifungal Drug Arsenal against Candida albicans. Antimicrob. Agents Chemother. 2013, 57, 3667-3675. [CrossRef] [PubMed]

26. Puig, M.; Moragrega, C.; Ruz, L.; Calderã, C.E.; Cazorla, F.M.; Montesinos, E.; Llorente, I. Interaction of antifungal peptide BP15 with Stemphylium vesicarium, the causal agent of brown spot of pear. Fungal Biol. 2016, 120, 61-71. [CrossRef] [PubMed]

27. Osmond, R.I.W.; Hrmova, M.; Fontaine, F.; Imberty, A.; Fincher, G.B. Binding interactions between barley thaumatin-like proteins and (1,3)- $\beta$-D-glucans. FEBS J. 2001, 268, 4190-4199. [CrossRef]

28. Xi, Y.; Jiao, W.; Cao, J.; Jiang, W. Effects of chlorogenic acid on capacity of free radicals scavenging and proteomic changes in postharvest fruit of nectarine. PLOS ONE 2017, 12, e0182494. [CrossRef] [PubMed]

29. Bradford, M.M. A Rapid and Sensitive Method for Quantitation of Microgram Quantities of Protein Utilizing the Principle of Protein-Dye Binding. Anal. Biochem. 1976, 72, 248-254. [CrossRef]

30. Yang, X.; Kang, M.C.; Li, Y.; Kim, E.A.; Kang, S.M.; Jeon, Y.J. Asperflavin, an Anti-Inflammatory Compound Produced by a Marine-Derived Fungus, Eurotium amstelodami. Molecules 2017, 22, 1823. [CrossRef] [PubMed]

31. Laemmli, U.K. Cleavage of Structural Proteins during the Assembly of the Head of Bacteriophage T4. Nature 1970, 227, 680-685. [CrossRef] [PubMed]

32. Nesterenko, M.V.; Tilley, M.; Upton, S.J. A simple modification of Blum's silver stain method allows for 30 minutes detection of proteins in polyacrylamide gels. J. Biochem. Biophys. Meth. 1994, 28, 239-242. [CrossRef]

33. Sharma, N.; Tripathi, A. Effects of Citrus sinensis (L.) Osbeck epicarp essential oil on growth and morphogenesis of Aspergillus niger (L.) Van Tieghem. Microbiol. Res. 2008, 163, 337-344. [CrossRef] [PubMed]

34. Da Rocha Neto, A.C.; Maraschin, M.; Di Piero, R.M. Antifungal activity of salicylic acid against Penicillium expansum and its possible mechanisms of action. Int. J. Food Microbiol. 2015, 215, 64-70. [CrossRef] [PubMed]

35. Theis, T.; Marx, F.; Salvenmoser, W.; Stahl, U.; Meyer, V. New insights into the target site and mode of action of the antifungal protein of Aspergillus giganteus. Res. Microbiol. 2005, 156, 47-56. [CrossRef] [PubMed]

36. Li, B.Q.; Tian, S.P. Effects of trehalose on stress tolerance and biocontrol efficacy of Cryptococcus laurentii. J. Appl. Microbiol. 2006, 100, 854-861. [CrossRef] [PubMed]

37. Tao, N.; Ouyang, Q.; Jia, L. Citral inhibits mycelial growth of Penicillium italicum by a membrane damage mechanism. Food Control 2014, 41, 116-121. [CrossRef]

38. Yun, J.; Lee, H.; Ko, H.J.; Woo, E.R.; Lee, D.G. Fungicidal effect of isoquercitrin via inducing membrane disturbance. Biochim. Biophys. Acta 2015, 1848, 695-701. [CrossRef] [PubMed]

39. Cerioni, L.; Volentini, S.I.; Prado, F.E.; Rapisarda, V.A.; Rodríguez-Montelongo, L. Cellular damage induced by a sequential oxidative treatment on Penicillium digitatum. J. Appl. Microbiol. 2010, 109, 1441-1449. [CrossRef] [PubMed]

40. Wang, W.; Deng, L.; Yao, S.; Zeng, K. Control of green and blue mold and sour rot in citrus fruits by the cationic antimicrobial peptide PAF56. Postharvest Biol. Technol. 2018, 136, 132-138. [CrossRef]

41. Li, J.; Bao, X.; Xu, Y.; Zhang, M.; Cai, Q.; Li, L.; Wang, Y. Hypobaric storage reduced core browning of Yali pear fruits. Sci. Hortic. 2017, 225, 547-552. [CrossRef]

Sample Availability: Samples of the compounds are not available from the authors. 
(C) 2018 by the authors. Licensee MDPI, Basel, Switzerland. This article is an open access article distributed under the terms and conditions of the Creative Commons Attribution (CC BY) license (http:/ / creativecommons.org/licenses/by/4.0/). 